\title{
1.229 CASOS DE ABORTO EN EL HOSPITAL UNIVERSITARIO DE CALDAS
}

Universidad de Caldas - Facultad de Medicina - Departamento de Ginecología y Obstetricia Unidad Obstétrica - Noviembre 1969

Dr. Octavio Vélez Ramírez*

\section{INTRODUCCION}

El aborto es el accidente más frecuente de la Patología Obstétrica e influye no sólamente en la pérdida potencial de gran número de vidas sino también en la frecuencia de los índices de Morbilidad y Mortalidad maternos.

El mayor número de abortos ocurre entre las semanas octava y duodécima pero hay muchos casos, de las primeras semanas, que transcurren en forma inadvertida porque se piensa en irregularidades y trastornos menstruales, sin sospechar la gestación.

Es problema complejo determinar la frecuencia del aborto. Se afirma que el $10 \%$ de los Embarazos terminan en aborto, pero la mayoría de los estudios realizados sobre el particular se refieren a material hospitalario el cual no refleja lo que realmente acontece en las comunidades donde él se origina, especialmente el criminal y clandestino cuya frecuencia aumenta notablemente en las vastas agrupaciones urbanas. Dexeus (4) calcula 1 aborto por cada 3-4 partos y afirma que la mayoría de ellos son provocados.
En los Estados Unidos se calcula que el número de abortos fluctúa entre 200.000 y $1^{\prime} 200.444$ por año (18).

En el Hospital Universitario de Caldas llama la atención el elevado número de diagnósticos de aborto hecho en el Servicio de Obstetricia. Conscientes de este problema nos proponemos analizarlo para valorar la incidencia del aborto hospitalario entre nosotros y estudiar las características y modalidades del mismo en nuestro medio.

Entre el 10 de Enero de 1966 al 31 de Diciembre de 1968 hubo 8.835 hospitalizaciones en el Servicio de Maternidad del Hospital Universitario de Caldas.

Estos Ingresos se discriminan así:

CUADRO № 1

DISTRIBUCION DE LAS 8.835 PACIENTES SEGUN CAUSAS DE INGRESO

MANIZALES - 1966-1968 HOSPITALIZACIONES

\begin{tabular}{lcr}
\hline Causas de Ingreso & No de Casos & \multicolumn{1}{c}{$\%$} \\
\hline Parto & 6.586 & 74,5 \\
Aborto & 1.229 & 14,0 \\
Embarazo ectópico & 94 & 1,0 \\
Otras causas & 926 & 10,5 \\
& 8.835 & 100,0 \\
\hline
\end{tabular}

* Jefe Unidad Obst trica - Hospital Universitario de Caldas. 


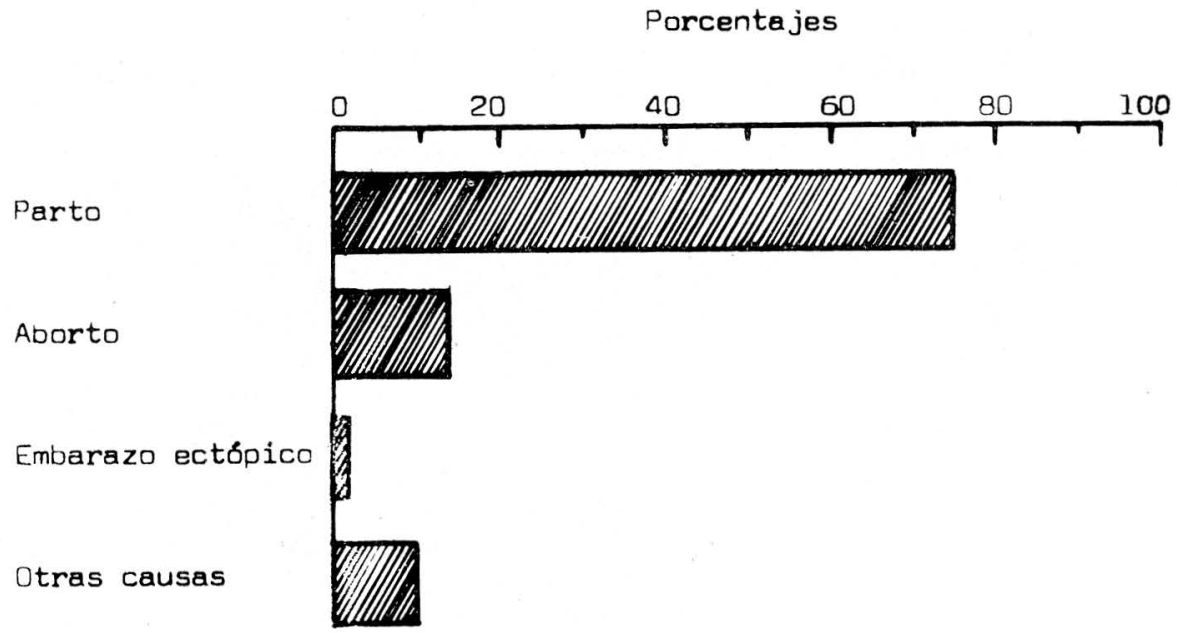

GRAFICA No 1

\section{Material y Métodos}

El $14,0 \%$ de las pacientes se hospitalizó por aborto.

La revisión y análisis de las historias clínicas correspondientes constituye el objeto del presente trabajo.

El diagnóstico de Aborto se hizo teniendo en cuenta los hallazgos obtenidos en la exploración física, exámenes de Laboratorio (Galli Mainini) y el estudio Anatomopatológico de los tejidos extraídos por el raspado uterino.

Desafortunadamente el examen histológico, el cual tiene importancia indiscutible, no fue verificado en todos los casos, y en los que no lo fué, el diagnóstico se confirmó por las reacciones del Laboratorio (Galli Mainini), los datos hallados al examen clí- nico y la presencia de signos macroscópicos evidentes de aborto. Los casos dudosos se descartaron.

\section{Resultados y Comentarios}

Como resultados del presente estudio se obtuvieron los siguientes:

CUADRO N: 2

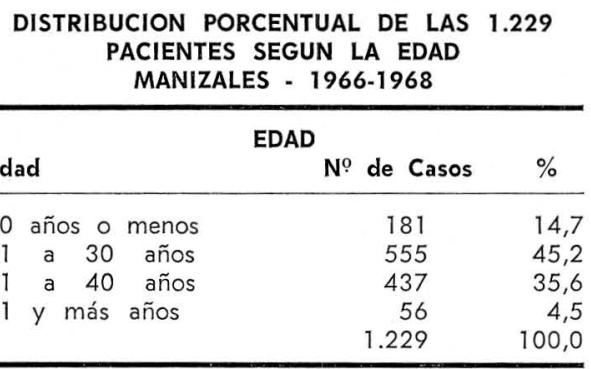

Encontramos la mayor frecuencia entre los decenios tercero y cuarto de la vida. La paciente de menos 


\section{DISTRIBUCION PORCENTUAL DE 1229 PACIENTES SEGUN PROCEDENCIA}

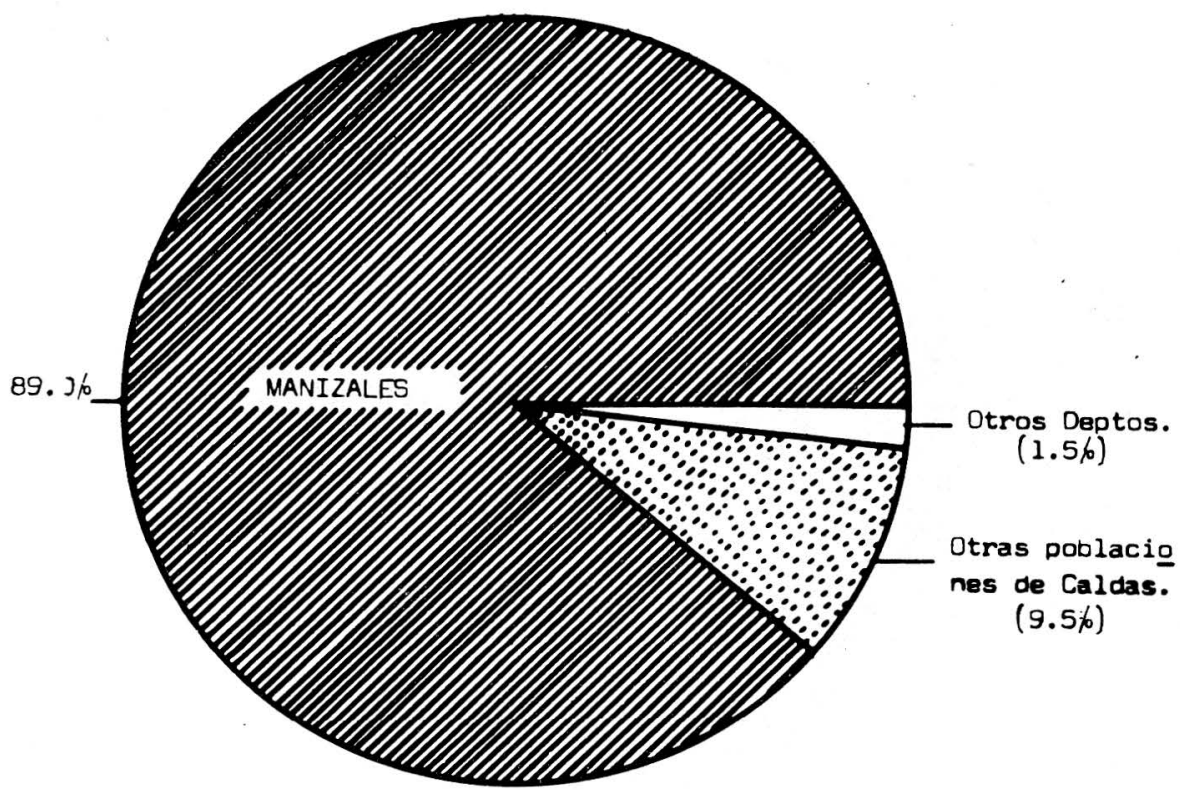

GRAFICA NN 2

edad fue de 14 años y la mayor edad, de 48 años. El promedio de edad fue de 28,4 años. El $80 \%$ de las pacientes fluctúa entre los 21 y 40 años de edad lo cual resulta explicable por la mayor actividad sexual en estas edades.

\section{CUADRO № 3}

DISTRIBUCION PORCENTUAL DE LAS 1.229 PACIENTES SEGUN SU PROCEDENCIA MANIZALES - 1966-1968

\begin{tabular}{|c|c|c|}
\hline \multicolumn{3}{|c|}{ PROCEDENCIA } \\
\hline Población & $N^{0}$ de Casos & $\%$ \\
\hline Manizales & 1.095 & 89,0 \\
\hline $\begin{array}{c}\text { Otras poblaciones } \\
\text { de Caldas }\end{array}$ & & \\
\hline $\begin{array}{l}\text { de Caldas } \\
\text { Otros Departamentos }\end{array}$ & 117 & $\begin{array}{l}9,5 \\
1,5\end{array}$ \\
\hline & 1.229 & 100,0 \\
\hline
\end{tabular}

El $89,0 \%$ de las pacientes procede de la ciudad de Manizales. El 11,\% restante corresponde a pacientes de otras poblaciones de Caldas y de otros departamentos. El porcentaje de estos últimos es sólo de 1,5\%. Llama la atención el porcentaje de pacientes de fuera de Manizales, máxime, si se tiene en cuenta que al Hospital Universitario de Caldas afluye en busca de servicios médicos una gran cantidad de pacientes que proviene no sólo de otras poblaciones de Caldas sino de otros Departamentos. En el caso del aborto solo llegan al Hospital los casos más complicados.

El $75,5 \%$ de las pacientes aparece como casadas. Creemos que esta cifra no es exacta porque resulta de los datos obtenidos por el interrogatorio de las enfermas a las cuales no 


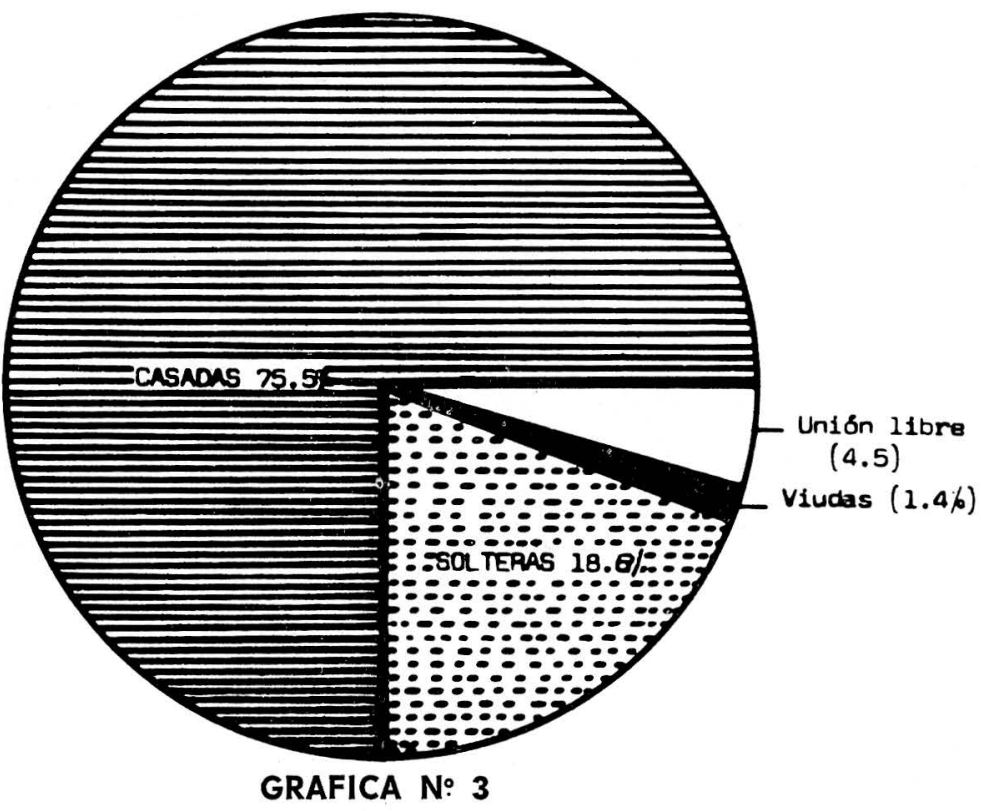

se les exige ningún documento de identificación y es usual en este tipo de clientela el interés por ocultar su verdadera identidad especialmente cuando el aborto es criminal.

\section{CUADRO NN 4}

\section{DISTRIBUCION PORCENTUAL DE LAS 1.229 PACIENTES SEGUN ESTADO CIVIL MANIZALES - 1966-1968}

\begin{tabular}{|c|c|c|}
\hline Estado civil & No de Casos & $\%$ \\
\hline Casadas & 928 & 75,5 \\
\hline Solteras & 228 & 18,6 \\
\hline Unión ilegal & 56 & 4,5 \\
\hline \multirow[t]{2}{*}{ Viudas } & 17 & 1,4 \\
\hline & 1.229 & 100,0 \\
\hline
\end{tabular}

El $18,6 \%$ admitió ser solteras seguidas por un margen muy estrecho de las que vivían en unión ilegal.
En relación con el estatus socioeconómico, un alto porcentaje presenta un bajo grado de cultura pues sólo tiene la instrucción correspondiente a los primeros años de enseñanza elemental $y$ un grupo reducido ha terminado el pensum del programa de primaria.

Son fercuentes los casos de analfabetismo y apenas un número muy escaso ha tenido aceso a los primeros años del bachillerato.

La generalidad de las pacientes pertenece a núcleos familiares de pocos ingresos y de recursos económicos limitados. En cantidad apreciable es manifiesta su franca hostilidad y rechazo a nuevos embarazos debido no solo al miedo y terror que tienen por 
el parto, el cual consideran como un momento de suspenso entre la vida y la muerte, sino también a las condiciones de miseria en que se deba- ten sus hogares. Lógicamente, estos factores desempeñan un papel muy importante en la frecuencia del aborto.

DISTRIBUCION PORCENTUAL DE 1229 PACIENTES SEGUN PROFESION U OFICIO

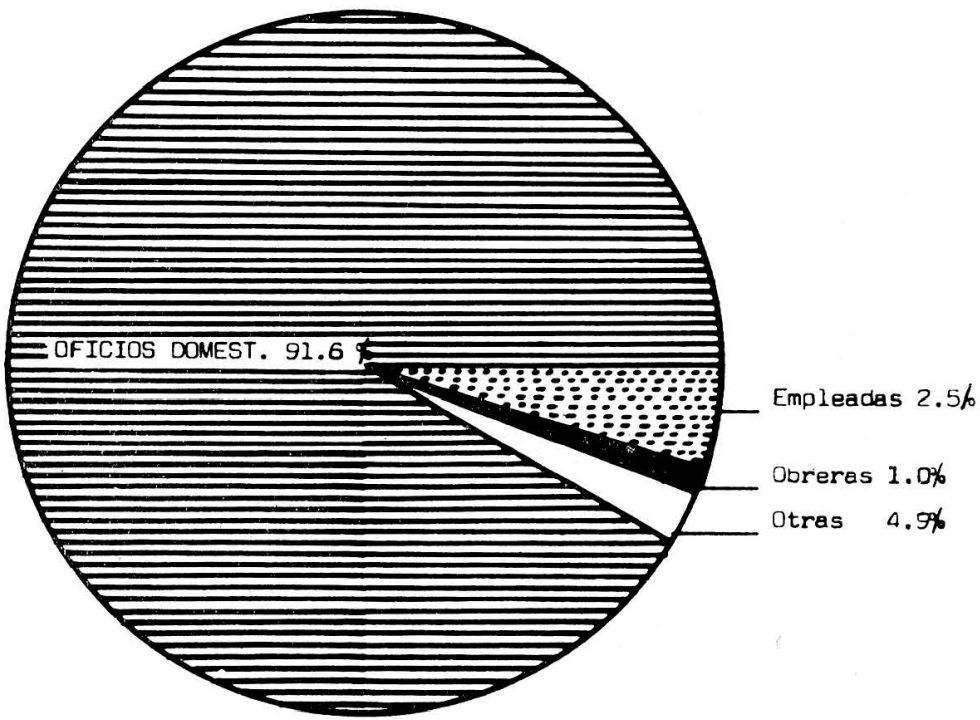

GRAFICA NN 4

\section{CUADRO NN 5}

DISTRIBUCION PORCENTUAL DE LAS 1.229

PACIENTES SEGUN PROFESION U OFICIO MANIZALES - 1966-1968

\begin{tabular}{|c|c|c|}
\hline Profesión & No de Casos & $\%$ \\
\hline Oficios domésticos & 1.126 & 91,6 \\
\hline Empleadas & 31 & 2,5 \\
\hline Obreras & 12 & 1,0 \\
\hline \multirow[t]{2}{*}{ Otras profesiones } & 60 & 4,9 \\
\hline & 1.229 & 100,0 \\
\hline
\end{tabular}

En relación con la profesión el $91,6 \%$ se dedica a los oficios domésticos y el $8,4 \%$ se distribuye entre empleadas, obreras y otros oficios. Consideramos que estos factores, especialmente los últimos inciden, co- mo en el caso anterior, en la frecuencia del aborto.

\section{CUADRO № 6}

DISTRIBUCION PORCENTUAL DE LAS 1.229

PACIENTES SEGUN LAS SEMANAS DEL EMBARAZO

MANIZALES - 1966-1968

\begin{tabular}{|c|c|c|c|c|c|}
\hline \multicolumn{3}{|c|}{ Semanas } & EDAD DEL & $\begin{array}{l}\text { EMBARAZO } \\
\mathbf{N}^{0} \text { de Casos }\end{array}$ & $\%$ \\
\hline 4 & a & 5 & & 12 & 1,0 \\
\hline 6 & a & 14 & & 922 & 75,0 \\
\hline 15 & a & 19 & & 205 & 16,7 \\
\hline \multirow[t]{2}{*}{20} & $y$ & más & & 90 & 7,3 \\
\hline & & & & 1.229 & 100,0 \\
\hline
\end{tabular}

El $75,0 \%$ de los abortos se presentó entre las 6 y las 14 semanas del embarazo. Esta frecuencia está de 


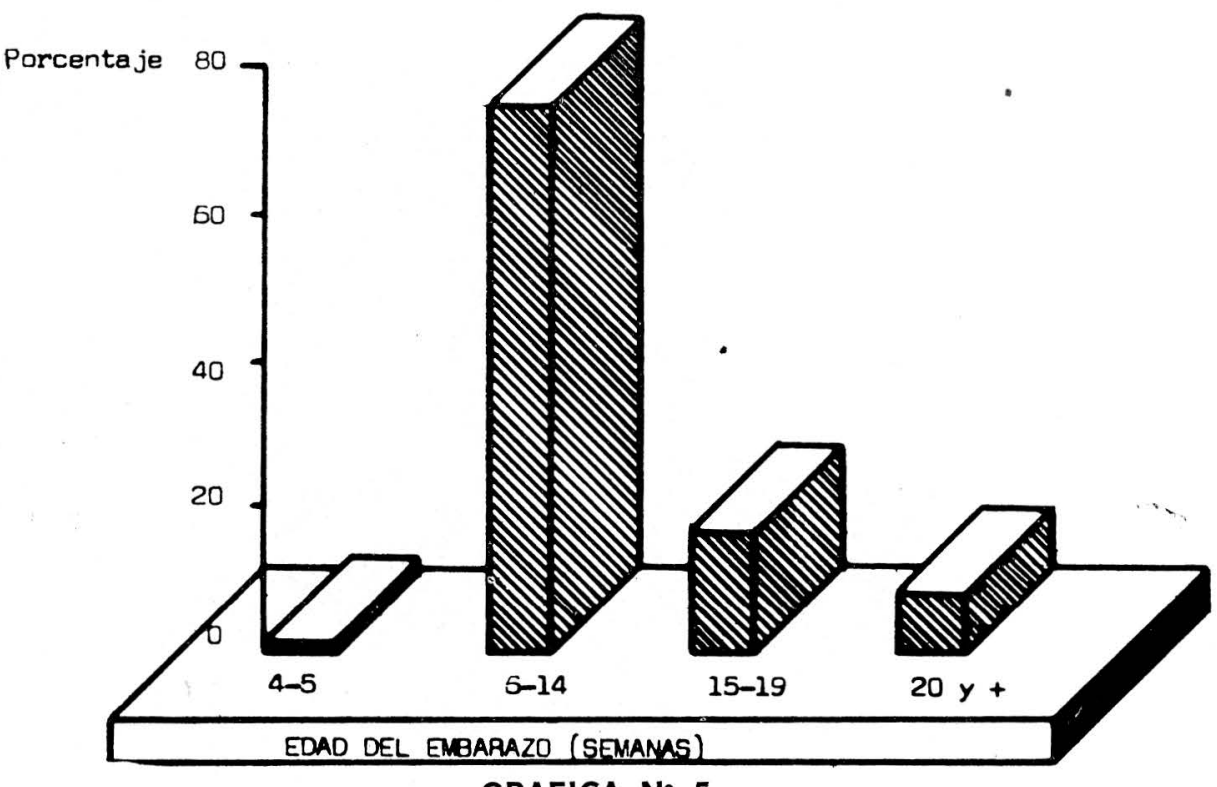

GRAFICA № 5

acuerdo con la reportada por otros autores (10) y confirma la influencia que tienen los factores ovulares maternos y emocionales en la etiología del aborto (5-9). El factor emocional influye durante todo el embarazo pero su acción se hace más notoria en esta edad de la gestación porque es la época en la cual la futura madre está en condiciones más desfavorables para adaptarse a su nuevo estado y en consecuencia reacciona fácilmente desencadenando el aborto (9).

El $90,6 \%$ de las pacientes no tenía control prenatal, a pesar de que el $75,0 \%$ de elas estaba entre el $2{ }^{\circ}$ y 3er. mes de gestación. Resalta el po-
Rev. Col. Obst. y Ginec. 
a múltiples causas entre las cuales juega papel primordial el factor socioeconómico, la educación deficiente, el embarazo no deseado etc.

CUADRO N: 8

DISTRIBUCION PORCENTUAL DE LAS 1.229

PACIENTES SEGUN EL EMBARAZO ACT'JAL MANIZALES - 1966-1968

\begin{tabular}{lcr}
\hline & $\begin{array}{c}\text { GRAVIDEZ } \\
\text { Embarazo Actual }\end{array}$ & \\
\hline 1 & 101 & 8,2 \\
2 & 109 & 8,9 \\
3 & 100 & 8,2 \\
4 & 106 & 8,6 \\
5 & 107 & 8,7 \\
6 & 86 & 7,1 \\
7 & 90 & 7,3 \\
8 & 86 & 7,0 \\
9 & 87 & 7,0 \\
10 o más & 357 & 29,0 \\
& 1.229 & 100,0 \\
\hline
\end{tabular}

EL HOSPITAL UNIVERSITARIO DE CALDAS 153

Encontramos la mayor frecuencia de abortos en pacientes grávidas 10 - más seguida de mujeres con paridad de uno a cinco. Estos datos confirman lo que sostienen Juan León y col. (10) quienes afirman que los abortos son más comunes en las multigestantes que en las primigestantes.

La mayor frecuencia de abortos en las grandes multíparas tiene como causas principales las anomalías del huevo, las deficiencias y alteraciones del útero que favorecen las implantaciones viciosas y no permiten la buena nutrición del embrión. Consideramos que el factor emocional contribuye en forma importante si se tienen en cuenta las condiciones económicas y ambientales en que viven estas pacientes, afectadas por privaciones y

DISTRIBUCION PORCENTUAL DE 1.229 PACIENTES SEGUN ABORTOS ANTERIORES

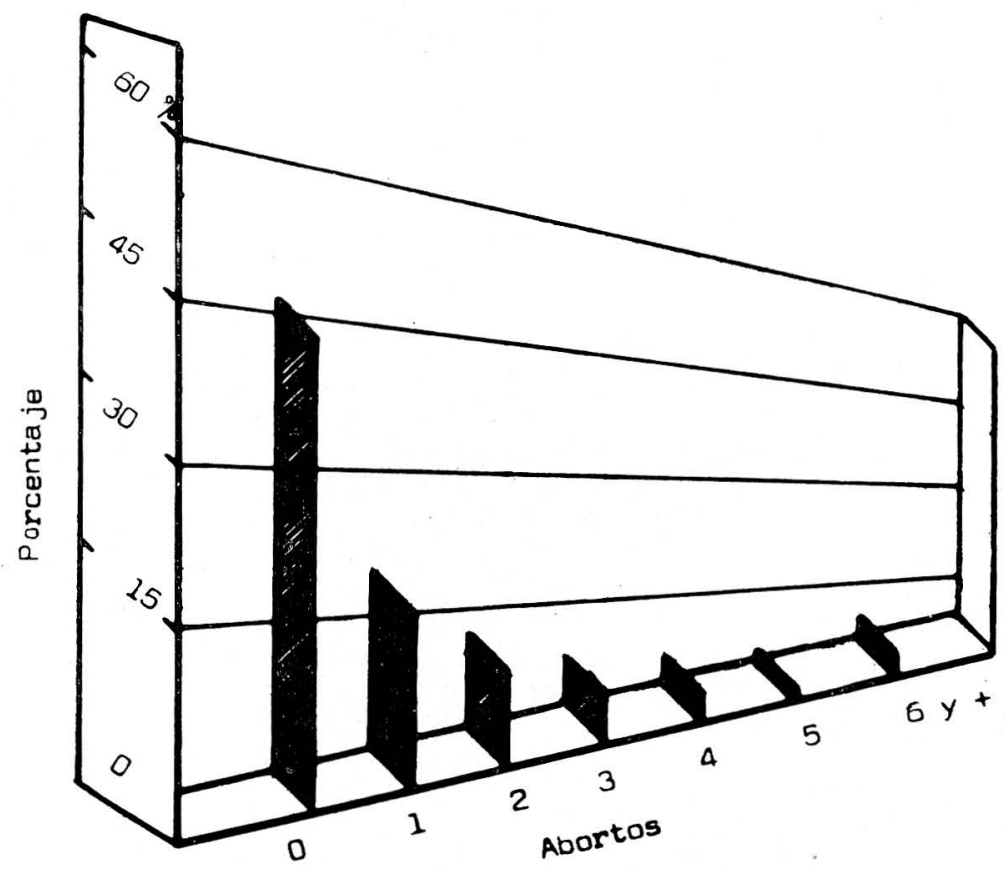

GRAFICA N: 6 
frustraciones diversas. Naturalmente estos hechos gravitan particularmente sobre la gestante que ya tiene (34-5) o más hijos y la condicionan síquicamente para esperar con angustia y desagrado el nacimiento de un hijo más porque ello significa ansiedad y pesadumbre en el transcurso del embarazo, miedo y terror durante el parto, además de la responsabilidad que conlleva una familia numerosa. En estas condiciones se aumentan las causas y mecanismos para abortar y lógicamente aparecen las pacientes "que abortan más fácilmente" como bien lo dice Isaza Mejía (9).

\section{CUADRO NN 9}

\section{DISTRIBUCION PORCENTUAL DE LAS 1.229 PACIENTES SEGUN ABORTOS ANTERIORES MANIZALES - 1966-1968}

\begin{tabular}{lcr}
\hline Abortos & $\begin{array}{c}\text { ABORTOS } \\
\text { ANTERIORES } \\
\mathbf{N}^{0} \text { de Casos }\end{array}$ & $\%$ \\
\hline Sin & 565 & 46,0 \\
$\vdots$ & 252 & 20,5 \\
2 & 159 & 12,9 \\
3 & 96 & 7,8 \\
4 & 61 & 5,0 \\
5 & 36 & 2,9 \\
6 o más & 60 & 4,9 \\
& 1.229 & 100,0 \\
\hline
\end{tabular}

Se encontró la mayor frecuencia de abortos en pacientes sin antecedentes de interrupción de embarazos anteriores seguida de aquellas que habían tenido uno y dos abortos previos.

Estas cifras no están de acuerdo con la teoría de Malpas (3), quien quería demostrar que el riesgo de aborto para una paciente se aumentaba en un $13 \%$ después de un aborto previo, un $37 \%$ después de 2 abortos y un $84 \%$ después de 3 abortos. Es decir, sostenía que las probabilidades de aborto se aumentaban con el número de abortos anteriores.
Duarte Contreras y col. (5) también reportan cifras que no confirman esta teoría.

En trece pacientes se encontraron antecedentes de 10 y más abortos anteriores hecho que es frecuente en nuestro medio. Una paciente abortadora habitual, tenía el antecedente de 24 abortos.

\section{CUADRO № 10}

\section{DISTRIBUCION PORCENTUAL DE LAS 1.229 PACIENTES SEGUN ANTECEDENTES QUIRURGICOS MANIZALES - 1966-1968}

\begin{tabular}{|c|c|c|}
\hline $\begin{array}{lc}\text { ANTECEDENTES } & \text { QUIRU } \\
\text { Intervención } & N^{0} d\end{array}$ & $\begin{array}{l}\text { URGICOS } \\
\text { de Casos }\end{array}$ & $\%$ \\
\hline Legrados uterinos & 317 & 25,7 \\
\hline Cesárea & 45 & 3,6 \\
\hline Apendicectomía & 41 & 3,3 \\
\hline Colecistectomía & 24 & 1,9 \\
\hline Amigdalectomía & 24 & 1,9 \\
\hline Herniorrafía & 18 & 1,4 \\
\hline Salpinguectomía & 17 & 1,3 \\
\hline Extirpación quiste ovario & 8 & 0,6 \\
\hline Corrección prolapso genital & 7 & 0,5 \\
\hline Tiroidectomía & 6 & 0,4 \\
\hline Extirpación mioma uterino & 3 & 0,2 \\
\hline Corrección labio leporino & 3 & 0,2 \\
\hline Corrección cistocele y rectocele & 2 & 0,1 \\
\hline Mastectomía & 1 & 0,08 \\
\hline Extirpación pólipo endocervical & 1 & 0,08 \\
\hline Extirpación sinequias uterinas & 1 & 0,08 \\
\hline Sin intervención & 776 & 63,1 \\
\hline
\end{tabular}

435 casos $(36,9 \%)$ tenían antecedentes de una o más intervenciones quirúrgicas. Los antecedentes quirúrgicos observados con más frecuencia fueron el legrado uterino $(25,7 \%)$, la cesárea $(3,6 \%)$ y la apendicectomía $(3,3 \%)$.

Nuestra opinión es la de que estos antecedentes tienen poca relación con la etiología del aborto, excepción hecha de las intervenciones practicadas sobre los órganos genitales que pueden ocasionar alguna lesión cervical especialmente a nivel del orificio interno como los raspados uterinos 
agresivos, la corrección de un prolapso genital y las secuelas dejadas por maniobras obstétricas en partos laboriosos (3).

\section{CUADRO N: 11}

DISTRIBUCION PORCENTUAL DE LAS 1.229 PACIENTES SEGUN EDAD DE LA MENARQUIA

\begin{tabular}{|c|c|c|c|}
\hline \multicolumn{4}{|c|}{ MENARQUIA } \\
\hline Edad & $\mathbf{N}^{\mathbf{9}}$ & de Casos & $\%$ \\
\hline 10 & & 8 & 0,7 \\
\hline 11 & & 30 & 2,4 \\
\hline 12 & & 176 & 14,3 \\
\hline 13 & & 275 & 22,4 \\
\hline 14 & & 304 & 24,7 \\
\hline 15 & & 174 & 14,2 \\
\hline 16 & & 68 & 5,6 \\
\hline 17 & & 25 & 2,0 \\
\hline 18 & & 3 & 0,2 \\
\hline 19 & & 2 & 0,2 \\
\hline Sin dato & & 164 & 13,3 \\
\hline \multicolumn{4}{|c|}{ Edad promedio 13,7} \\
\hline & & 1.229 & 100,0 \\
\hline
\end{tabular}

La mayor frecuencia de abortos la encontramos en aquellas pacientes cuya primera menstruación apareció a los 14 años de edad, seguida de mujeres que presentaron su menarquia a los 13 años.

La edad promedio de la menarquia en el grupo de estudio fue de 13,7. Estos datos son mu" semejantes a las cifras anotadas por otros autores (5).

Al examen clínico se encontró patología ginecológica asociada en 484 casos $(39,4 \%)$. La patología más frecuentemente reportada fue la cervicitis $(22,2 \%)$, el prolapso genital (16,$5 \%)$ y la retroversoflexión uterina $(12,4 \%)$, seguida de infección por tricomonas $(6,4 \%)$ y neisseria gonorrheae $(6,3 \%)$.

Consideramos que los procesos inflamatorios y la retroversoflexión fija uterina son factores importantes en la etiología del aborto espontáneo.

\section{CUADRO N: 12}

DISTRIBUCION PORCENTUAL DE LAS 1.229 PACIENTES SEGUN PATOLOGIA GINECOLOGICA ASOCIADA

MANIZALES - 1966-1968

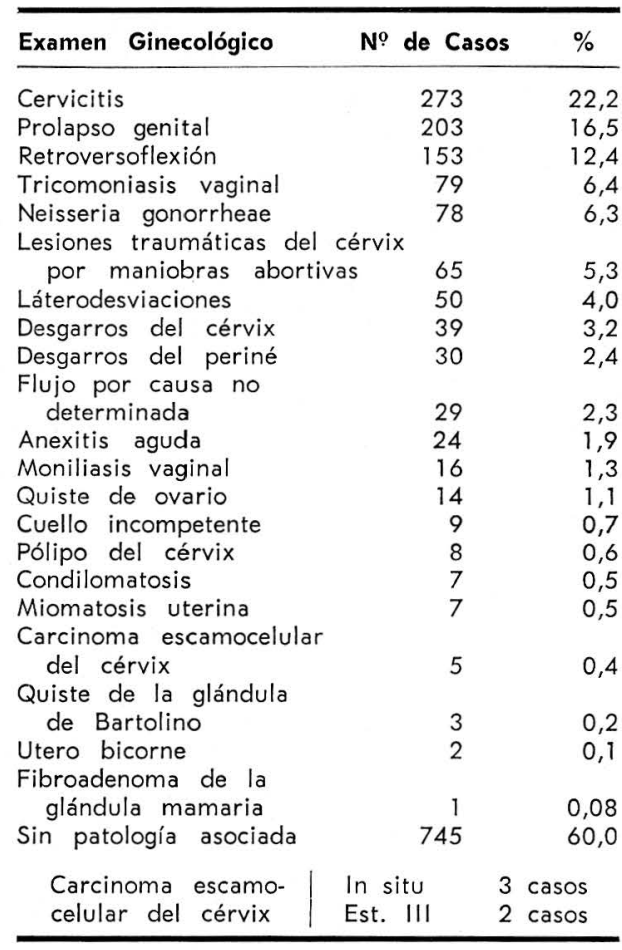

Se sabe que las adherencias dejadas por los procesos infecciosos fijan ulteriormente el útero y actúan como facióres mecánicos de aborto, al dificultar el crecimiento del órgano.

Otros factores como las malas condiciones de la caduca, desarrollada a expensas de un endometrio preparado inadecuadamente, con disminución de la irrigación sanguínea, los tumores uterinos, las malformaciones uterinas y el prolapso genital predisponen igualmente al aborto debido a que las condiciones para la anidación no son adecuadas y al desarrollarse 
el feto la cavidad resulta demasiado reducida.

\section{CUADRO № 13}

DISTRIBUCION PORCENTUAL DE LAS PACIENTES SEGUN PATOLOGIA CONCOMITANTE

MANIZALES - 1966.1968

\begin{tabular}{|c|c|c|}
\hline Entidade línica & de Casos & $\%$ \\
\hline Focos sépticos dentarios & 345 & 28,0 \\
\hline Várices miembros inferiores & 304 & 24,7 \\
\hline Infecciones urinarias & 159 & 12,9 \\
\hline $\begin{array}{l}\text { Parasitismo intestinal } \\
\text { Cardiopatías (ductus arte- }\end{array}$ & 104 & 8,4 \\
\hline riovenoso 1 caso) & 72 & 5,8 \\
\hline Infeciones amigdalianas & 59 & 4,8 \\
\hline Infecciones respiratorias & 43 & 3,5 \\
\hline Hernias & 36 & 2,9 \\
\hline $\begin{array}{l}\text { T.B.C. (TBC renal } 2 \text { casos, } \\
\text { Mal de Pott 1) }\end{array}$ & 28 & 2,3 \\
\hline Amebiasis intestinal & 23 & 1,8 \\
\hline $\begin{array}{l}\text { Afecciones vesiculares } \\
\text { colec. colelit.) }\end{array}$ & 19 & 1,5 \\
\hline $\begin{array}{l}\text { Enfermedad vascular } \\
\text { hipertensiva }\end{array}$ & & \\
\hline $\begin{array}{l}\text { nipertensiva } \\
\text { Trastornos mentales }\end{array}$ & $\begin{array}{l}16 \\
15\end{array}$ & $\begin{array}{l}1,3 \\
1,2\end{array}$ \\
\hline Bocio & 11 & 0,9 \\
\hline Dermatitis & & \\
\hline (psoriasis 2 casos) & 11 & 0,9 \\
\hline Asma bronquial & 10 & 0,8 \\
\hline Signos de desnutrición & 10 & 0,8 \\
\hline Flebitis en miembros & & \\
\hline inferiores & 9 & 0,7 \\
\hline Epilepsia & 7 & 0,6 \\
\hline Diabetes & 5 & 0,4 \\
\hline Enterocolitis & 5 & 0,4 \\
\hline Hiperemesis gravídica & 4 & 0,3 \\
\hline Ulcera péptica & 3 & 0,2 \\
\hline Infecciones de los senos nasale & es 2 & 0,1 \\
\hline Hepatitis & 2 & 0,1 \\
\hline Paladar hendido & 1 & 0,08 \\
\hline Hemorroides & 1 & 0,08 \\
\hline Papiloma nasal & 1 & 0,08 \\
\hline Enfermedad de Rynod & 1 & 0,08 \\
\hline Sin patología concomitante & 429 & 35,0 \\
\hline
\end{tabular}

Se encontró patología sobreagregada en 800 pacientes $(65 \%)$.

La patología más frecuentemente observada fue focos sépticos denta- rios $(28,0 \%$ ) y el parasitismo intestinal $(8,4 \%)$. (Esta última entidad solo se reportó cuando se comprobó por examen de Laboratorio).

Las infecciones focales son importantes porque los gérmenes procedentes de diferentes partes infectadas del organismo pueden colonizar a nivel de la decidua $y$, al alcanzar el embrión determinan el aborto. El agente causal ordinariamente es el estreptococo. En aquellos casos de aborto en los cuales no se encuentre una explicación satisfactoria no debe olvidarse la posible existencia de un foco séptico (4).

Pueden las enfermedades del aparato urinario ser causa de aborto como las nefropatías crónicas, la litiasis y las fístulas. Hunner citado por Dexeus Font (4) refiere casos de aborto en los cuales se observa una mayor participación etiopatogénica de procesos de pielitis concomitantes con estenosis ureteral.

Beck (19) encuentra bacteriemia asintomática en un 4 a 6 por 100 de las embarazadas y anota que las infecciones urinarias predisponen a una mayor frecuencia de parto prematuro.

Otros estados como el parasitismo intestinal y la anemia asociados con una dieta deficiente, mal equilibrada, insuficiente en proteínas, lípidos, hidratos de carbono, minerales, vitaminas etc. son factores que debilitan y deterioran las defensas orgánicas de la embarazada creando condiciones que pueden determinar la interrupción de la gestación y naturalmente coadyuvan en la frecuencia del aborto. 


\section{Causas del Aborto}

CUADRO NN 14

DISTRIBUCION PORCENTUAL DE LAS 1.229

PACIENTES SEGUN CAUSAS DEL ABORTO MANIZALES - 1966-1968

\begin{tabular}{|c|c|c|}
\hline Causas & $\mathrm{N}^{0}$ de Casos & $\%$ \\
\hline Sin causa conocida (1) & 996 & 81,0 \\
\hline Aborto provocado & 147 & 12,0 \\
\hline Antecedentes traumáticos & 43 & 3,5 \\
\hline \multirow[t]{2}{*}{ Aborto molar } & 43 & 3,5 \\
\hline & 1.229 & 100,0 \\
\hline
\end{tabular}

(1) Incluye 130 casos de aborto habitual $(10,5 \%)$.

Uno de los problemas complejos en el aborto es el que plantea la determinación de su causa. Esta es la razón por la cual el $81,0 \%$ de nuestros casos aparece sin causa conocida. Hertig y Sheldon (15) sostienen que el $52,1 \%$ de los abortos se debe a anormalidades de orden genético que conducen a la formación de huevos patológicos los cuales terminan en aborto. Se ha comprobado que una causa común de aborto puede ser el medio ambiente anormal en el cual se cumple el desarrollo del embrión que resulta a partir de un huevo patológico o de una función uterina anormal (3).

Finalmente otros abortos son provocados o bien su causa reside en otros factores de orden materno, paterno u ovular que influyen en la incidencia del aborto. La multiplicidad y variabilidad de las causas potenciales del aborto fueron las razones fundamentales que nos impidieron sacar conclusiones definitivas del problema.

Los abortos traumáticos comprenden: a) Los consecutivos a una caída violenta, a un golpe en las proximidades del útero grávido, un accidente automoviliario o de cualquier otro origen etc. y b) $\mathrm{El}$ aborto provocado criminal (4).

DISTRIBUCION PORCENTUAL DE LAS 1229 PACIENTES SEGUN CAUSAS DEL ABORTO

Sin causa conocida

Porcentaje

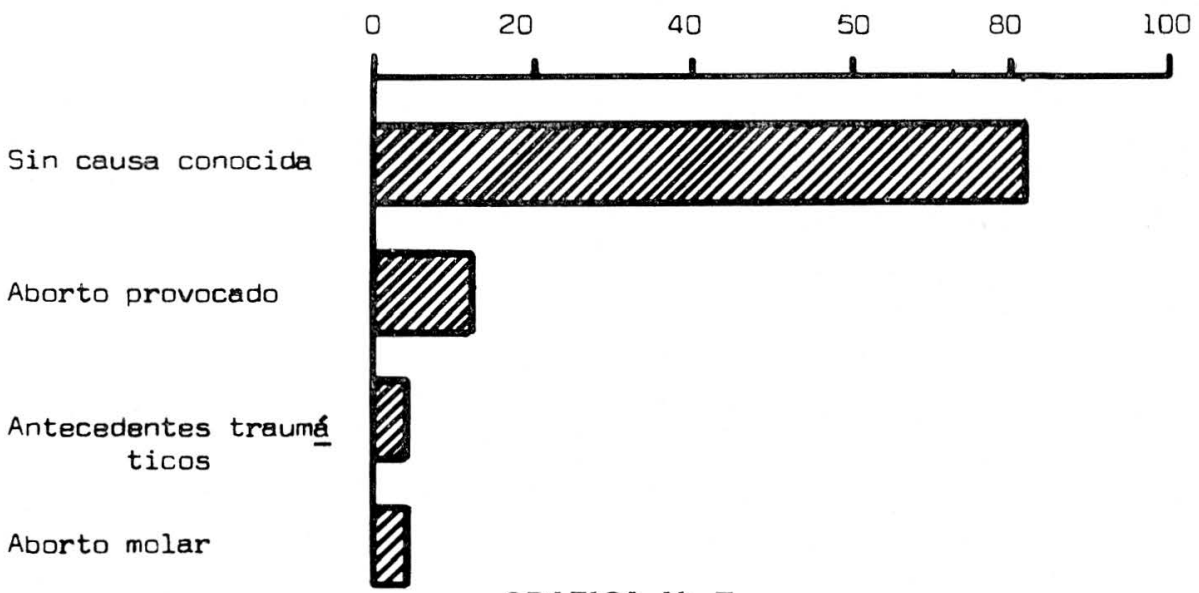

GRAFICA № 7 
El embarazo normal presenta una gran resistencia a los traumatismos uterinos externos e internos. Merger (11) sostiene que los traumatismos únicos, incluso violentos, son raras causas del aborto, pero pueden originar la interrupción de un embarazo ya comprometido.

Lo cierto es que en el grupo de los abortos traumáticos entran en realidad numerosos casos en los cuales aparentemente el traumatismo es el factor causal.

En las pacientes estudiadas encontramos 147 casos $(12,0 \%)$ con aborto provocado criminal comprobado $y$ 43 casos $(3,5 \%)$ que presentaron antecedentes de una caída, golpes recibidos sobre la región del hipogastrio, viajes largos y prolongados en automóvil o en otros vehículos, etc. En nuestra experiencia gran número de pacientes con aborto criminal tratan de ocultar la causa real del aborto atribuyéndola a alguno de los factores traumáticos anteriormente citados. Esto nos induce a pensar que nuestra incidencia de aborto criminal es realmente mucho más alta.

\section{Clasificación Clínica del Aborto}

\section{CUADRO N 15}

DISTRIBUCION PORCENTUAL DE LAS 1.229 PACIENTES SEGUN DIAGNOSTICO AL INGRESO

$$
\text { MANIZALES - 1966-1968 }
$$

\begin{tabular}{lcr}
\hline Diagnóstico & No de Casos & \multicolumn{1}{c}{$\%$} \\
\hline Aborto incompleto & 1.008 & 82,0 \\
Aborto en curso & 196 & 16,0 \\
Aborto diferido & 19 & 1,5 \\
Aborto completo & 6 & 0,5 \\
& 1.229 & 100,0 \\
\hline
\end{tabular}

El $82,0 \%$ de las pacientes vino al Hospital en la etapa clínica de abor- to incompleto. Realmente fueron muy pocas las que consultaron cuando estaban en la etapa de amenaza de aborto. Creemos que esto se debe: 19) A la mentalidad de la gran mayoría de nuestras pacientes las cuales solo van al médico cuando el cuadro se complica por hemorragia 0 infección. $2^{\circ}$ ) El $75 \%$ de los casos estudiados estaba entre la 6a y la 14a semanas de gestación época en la cual en el mecanismo del aborto hay una mayor tendencia a la expulsión del feto y a la retención del resto del huevo y de la decidua debido a la mejor fijación de las vellosidades coriónicas, lo cual determina que la hemorragia benigna o profusa continúe hasta que los restos retenidos se expulsen espontáneamente o sean extraídos. Si este proceso no se cumple aparecen las condiciones ideales para la infección.

CUADRO N: 16

DISTRIBUCION PORCENTUAL DE LAS 1.229

PACIENTES SEGUN SINTOMA PREDOMINANTE

MANIZALES - 1966-1968

\begin{tabular}{lcr}
\hline \multicolumn{3}{c}{ SINTOMA PREDOMINANTE } \\
Síntoma & $\mathbf{N}^{0}$ de Casos & \multicolumn{1}{c}{$\%$} \\
\hline Hemorragia, dolor & 878 & 71,4 \\
Hemorragia, dolor, fiebre & 257 & 20,9 \\
Hemorragia & 71 & 5,8 \\
Dolor & 23 & 1,9 \\
& 1.229 & 100,0 \\
\hline
\end{tabular}

El $92,3 \%$ de las pacientes presentó como síntomas predominantes la hemorragia y el dolor. El 20,9\%, además de hemorragia y dolor, presentó fiebre. El dolor y la hemorragia se deben, el primero a las contracciones del miometrio y la segunda al desprendimiento del huevo. Como se puede observar los síntomas cue se encontraron con mayor frecuencia en estas pacientes fueron la hemorragia y el dolor asociados. 


\section{CUADRO N: 17}

DISTRIBUCION PORCENTUAL DE LAS 1.229

PACIENTES SEGUN LAS COMPLICACIONES POST-ABORTO

MANIZALES - 1966-1968

\begin{tabular}{lcc}
\hline $\begin{array}{c}\text { COMPLICACIONES } \\
\text { Complicaciones }\end{array}$ & $\begin{array}{c}\text { POST-ABORTO } \\
\mathbf{N}^{0} \text { de Casos }\end{array}$ & $\%$ \\
\hline Anemia & 166 & 13,6 \\
Shock hipovolémico & & \\
y anemia & 207 & 16,8 \\
Infección & 179 & 14,5 \\
Sin complicaciones & 67 & 55,1 \\
& 1.229 & 100,0 \\
\hline
\end{tabular}

El aborto se complica con retención ,hemorragia e infección (11). El $44,9 \%$ de los casos presentó complicaciones relacionadas con la hemorragia y la infección. En 207 casos $(16,8 \%)$ hubo shock post hemorrágico. Desde el punto de vista fisiopatológico la retención placentaria es muy frecuente y es causa de hemorragia e infección. Cuando la expulsión del huevo es natural y completa, eventualidad de mayor frecuencia en el aborto espontáneo, las complicaciones ocasionan menor morbilidad y son menos frecuentes. Las complicaciones son más graves y frecuentes en el aborto provocado criminal.

Aunque se afirma que la sífilis ha disminuído en los últimos 20 años (10) lo cierto es que se aprecia un aumento de su frecuencia en la clientela que acude al Hospital, especialmente al consultorio Prenatal y Salas de hospitalización obstétrica.

\section{CUADRO N: 18}

DISTRIBUCION PORCENTUAL DE LAS 1.229

PACIENTES CON EXAMEN SEROLOGICO MANIZALES - 1966-1968

\begin{tabular}{|c|c|c|}
\hline EXAMEN & $\begin{array}{l}\text { SEROLOGICO } \\
\mathrm{N}^{0} \text { de Casos }\end{array}$ & $\%$ \\
\hline $\begin{array}{l}\text { Con serología } \\
\text { Sin serología }\end{array}$ & $\begin{array}{r}963 \\
266 \\
1.229\end{array}$ & $\begin{array}{r}78,4 \\
21,6 \\
100,0\end{array}$ \\
\hline
\end{tabular}

DISTRIBUCION PORCENTUAL DE 1229 PACIENTES SEGUN COMPLICACIONES DE POSTABORTO

Anemia

Shock hipovolémico y anemia.

Infeccion

Sin complicaciones

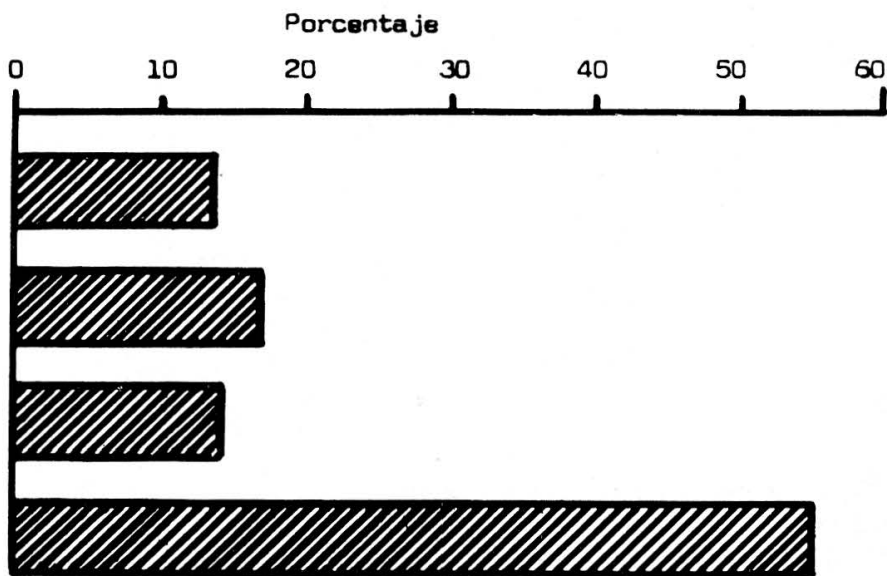

GRAFICA No 8 
CUADRO № 19

DISTRIBUCION PORCENTUAL DE LAS 963 PACIENTES SEGUN RESULTADO SEROLOGICO MANIZALES - 1966-1968

\begin{tabular}{lcr}
\hline Resultado & No de Casos & \multicolumn{1}{c}{$\%$} \\
\hline Reactiva & 77 & 8,0 \\
No reactiva & 886 & 92,0 \\
& 963 & 100,0 \\
\hline
\end{tabular}

En nuestro servicio, los reglamentos generales ordenan practicar sistemáticamente en toda embarazada el examen serológico el cual permite descubrir a menudo la sífilis latente - tardía que de otra manera pasaría desapercibida. Sólo en esta forma es factible iniciar un tratamiento precoz con agentes terapéuticos eficaces para prevenir y combatir los estragos de esta enfermedad.

En las pacientes estudiadas se practicó serología a $963(78,4 \%)$. Se obtuvieron los siguientes resultados: 886 serologías no reactivas y 77 reactivas, lo cual da una incidencia no depurada del $8,0 \%$.

Según Juan León (10), durante la gestación algunas reacciones serológicas pueden dar resultados positivos falsos, en una proporción que oscila entre el $1 \%$ y el $3 \%$ y considera que actualmente la asociación de sífilis y embarazo oscila entre el $0,3 \%$ y el $1,5 \%$.

Estas cifras comparadas con la incidencia encontrada por nosotros, aunque no depurada, nos habla en favor de una gran frecuencia de la asociación de sífilis-Embarazo en nuestro medio.

Merger (11) al considerar el problema de la sífilis y embarazo dice: "se ha repetido como un aforismo, durante mucho tiempo, que la "sífilis es la gran abortadora". Este slogan condenaba a tratamientos tan desagradables como inútiles a mujeres que habían sufrido abortos espontáneos. El estudio del aborto espontáneo demuestra que la sífilis es origen de modestos porcentajes (de 2 a $7 \%$ ). El aborto sifilítico tiene por caracteres ser tardío ( 5 meses) estar precedido de una fase más o menos larga de retención e implicar poca hemorragia".

\section{CUADRO N: 20}

DISTRIBUCION PORCENTUAL DE LAS 1.229 PACIENTES SEGUN EL TIEMPO TRANSCURRIDO ENTRE EL COMIENZO DE LOS SINTOMAS Y EL MOMENTO DE HOSPITALIACION MANIZALES - 1966-1968

\begin{tabular}{lrllcr}
\hline \multicolumn{2}{l}{ Tiempo en } & días & No & de Casos & $\%$ \\
\hline De & 1 & a & 10 & 948 & 77,1 \\
$\mathrm{De}$ & 11 & a & 20 & 170 & 13,8 \\
$\mathrm{De}$ & 21 & a & 30 & 48 & 3,9 \\
$\mathrm{De}$ & 31 & a & 40 & 8 & 0,7 \\
$\mathrm{De} 4$ & 41 & a & 90 & 17 & 1,4 \\
Sin dato & & 38 & 3,1 \\
& & & 1.229 & 100,0 \\
\hline
\end{tabular}

El $77,1 \%$ (948 casos) de las pacientes se demoraron entre 1 y 10 días para concurrir a la consulta del Hospital a partir del momento de la iniciación de los síntomas. El promedio global total fue de 7,3 días.

El 19,8\% (243) acudió al hospital en un tiempo que fluctúa entre 11 y 90 días después de haberse iniciado la sintomatología.

Como se anotó anteriormente, es usual en esta clase de pacientes buscar tardíamente la ayuda médica cuando ya las complicaciones no solamente han debilitado sus defensas sino que han ocasionado graves daños en órganos vitales.

Estancia pacientes 4.180 días, promedio de hospitalización: 3.4 días.

El 96,3\% ( 1.183 casos) permaneció de 1 a 10 días en el Hospital. El 


\section{CUADRO № 21}

\section{DISTRIBUCION PORCENTUAL DE LAS 1.229 \\ PACIENTES SEGUN TIEMPO DE \\ PERMANENCIA HOSPITALARIA \\ MANIZALES - 1966-1968}

\begin{tabular}{|c|c|c|c|c|c|}
\hline \multicolumn{2}{|c|}{ Días } & \multicolumn{2}{|c|}{ PERMANENCIA } & $\begin{array}{l}\text { HOSPITALARIA } \\
N^{0} \text { de Casos }\end{array}$ & $\%$ \\
\hline De & 1 & a & 10 & 1.183 & 96,3 \\
\hline $\mathrm{De}$ & 11 & a & 20 & 30 & 2,4 \\
\hline $\mathrm{De}$ & 21 & a & 30 & 7 & 0,6 \\
\hline $\mathrm{De}$ & 31 & a & 52 & 9 & 0,7 \\
\hline & & & & 1.229 & 100,0 \\
\hline
\end{tabular}

$3,7 \%$ (46 casos) estuvo hospitalizadas por un tiempo que fluctúa entre 11 y 52 días. Como datos extremos se enocntraron 3 pacientes que permanecieron en el hospital durante 4151-52 días respectivamente.

$\mathrm{Si}$ se tiene en cuenta que el $12 \%$ ( 147 casos) correspondía a abortos provocados criminales, el mayor tiempo de hospitalización fue empleado por casos sépticos. 289 casos (23,5\%) de aborto espontáneo sólo requirieron un día de hospitalización. La estancia pacientes alcanzó a 4.180 días y la permanencia hospitalaria global fue en promedio de 3,4 días.

No se hizo examen histológico en $212 \operatorname{casos}(17,2 \%)$.

Se encontró un elevado número de inflamaciones agudas así: Decidua con infiltrado inflamatorio agudo con presencia de vellosidades coriales 278 casos $(22,6 \%)$, Endometritis aguda post-aborto 88 casos $(7,2 \%)$, Placentitis 22 casos $(1,8 \%)$, Inflamación aguda de los vasos del cordón umbilical 4 casos $(0,3 \%)$ y Miometritis aguda post aborto 1 caso $(0,08 \%)$. Este hecho tiene importancia por

\section{Resultados Anatomopatológicos}

\section{CUADRO № 22}

\section{DISTRIBUCION PORCENTUAL DE LAS PACIENTES SEGUN ESTUDIO HISTOLOGICO DEL MATERIAL EXTRAIDO POR LEGRADO UTERINO MANIZALES - $1966-1968$}

\begin{tabular}{|c|c|c|}
\hline Estudio Histológico & $N^{0}$ de Casos & $\%$ \\
\hline Vellosidades con estroma, trofoblasto, vasos y decidua normales & 364 & 29,6 \\
\hline Vellosidades y decidua con infiltrado inflamatorio de tipo agudo & 278 & 22,6 \\
\hline Endometritis aguda post-aborto & 88 & 7,2 \\
\hline Vellosidades coriales y decidua con cambios necróticos y hemorragia & 60 & 4,9 \\
\hline Vellosidades coriales con edema & 53 & 4,3 \\
\hline Mola Hidatiforme & 43 & 3,5 \\
\hline Infarto placentario & 35 & 2,8 \\
\hline $\begin{array}{l}\text { Placenta con áreas de necrosis fibrinoide, hilinización y decidua uterina } \\
\text { con signos de autólisis }\end{array}$ & 35 & 2,8 \\
\hline Placentitis & 22 & 1,8 \\
\hline $\begin{array}{l}\text { Placenta con áreas extensas de necrosis con zonas de calcificación: Infil- } \\
\text { tración calcárea de la placenta }\end{array}$ & 16 & 1,3 \\
\hline $\begin{array}{l}\text { Cortes de decidua uterina necrótica con colonias bacterianas y sin } \\
\text { reacción leucocitaria }\end{array}$ & 11 & 0,9 \\
\hline Inflamación aguda de los vasos del cordón umbilical & 4 & 0,3 \\
\hline Sífilis placentaria & 2 & 0,1 \\
\hline Endometritis sincitial & 2 & 0,1 \\
\hline $\begin{array}{l}\text { Decidua uterina con zonas glandulares en las que se ven frecuentes pe- } \\
\text { nachos "Signo de Arias Stella" }\end{array}$ & 2 & 0,1 \\
\hline $\begin{array}{l}\text { Decidua uterina y vellosidades coriales con extensa necrosis fibrinoide y } \\
\text { escasa reacción celular }\end{array}$ & 1 & 0,08 \\
\hline Miometritis aguda post-aborto & 1 & 0,08 \\
\hline Sin dato & 212 & 17,2 \\
\hline
\end{tabular}


cuanto se ha dicho que la presencia de inflamación concomitante con vellosidades normales, permite sospechar el aborto criminal (9).

Se reportaron 53 casos $(4,3 \%)$ de vellosidades coriales con edema, proceso degenerativo, que puede resultar de los trastornos circulatorios que ocurren, particularmente cuando muere el embrión o el feto. La lesión edematosa, hidrópica, de la vellosidad corial se ha encontrado al estudio histológico de los especímenes de aborto espontáneo. Isaza Mejía (9) reporta este trastorno en el $24,8 \%$ sobre 137 preparaciones histológicas por aborto conjuntamente con otras alteraciones degenerativas de las vellosidades coriales.

Se encontraron 43 casos (3,5\%) de Mola Hidatiforme. El diagnóstico se comprobó tanto al examen macroscópico por la visualización de los racimos formados por las vellosidades vesiculares como por el examen histológico.

Se reportan diversas alteraciones placentarias tales como el infarto $y$ la presencia de áreas de necrosis fibrinoide. Novak (15) dice que estas lesiones se deben a la necrosis isquémica de las vellosidades, debida a trastornos circulatorios de la sangre materna en la decidua a lo cual coadyuvan los depósitos de fibrina colectados entre las vellosidades coriales. En 70 casos $(5,6 \%)$ de nuestro estudio se encontraron estas alteraciones degenerativas.

En relación con la sífilis placentaria se encontraron 2 casos $(0,1 \%)$ en el estudio histológico. Creemos que el hallazgo de esta patología, si se le investiga específicamente, puede ser más frecuente, dada la concomitancia de la sífilis y embarazo en nuestro medio.
La endometritis sincitial, de la cual se reportan 2 casos $(0,1 \%)$ indica la infiltración del trofoblasto (sobre todo por el sincitio) en la pared uterina, con notable reacción inflamatoria e incluso fenómenos necróticos. Aparece con más frecuencia después de un aborto especialmente después de los legrados que se practican con motivo de Molas Hidatiformes.

El signo de Arias Stella, caracterizado por la presencia de glándulas endometriales en forma de penacho, se encontró en 2 casos $(0,1 \%)$. Algunos autores (9) sostienen que autoriza para hacer el diagnóstico de Embarazo ectópico. Mackles y col., Pildes y Wheeler citados por Novak (15) han observado y consideran con valor diagnóstico estas modificaciones atípicas del endometrio en las mujeres que albergan un Embarazo ectópico. En los 2 casos estudiados por nosotros no se encontró Embarazo ectópico.

\section{Consideraciones sobre el Aborto Séptico en nuestro medio}

Entre las complicaciones que el médico debe afrontar en el campo obstétrico la infección constituye una de las más serias y frecuentes. Es una de las causas de mayor mortalidad materna en nuestro medio, a pesar de todos los recursos que hoy se tienen para combatirla.

El aborto incompleto es la patología más constante de los servicios obstétricos y es el factor que condiciona la mayor parte de las complicaciones sépticas. Diversos estudios han tratado de valorar estadísticamente el problema en nuestro país. Peralta Cayón (17) encuentra en varios años una frecuencia del $20 \%$ de abortos y Muñoz Delgado y col. (13) anotan la misma incidencia para la ciudad de Cali. 
Pardo Vargas y col. (16) anotan que durante el año de 1965 fueron atendidos en el país, en medio hospitalario, 280.671 partos y 56.438 abortos; es decir que por cada 5 partos hubo un aborto.

Nosotros encontramos sobre 8.835 pacientes hospitalizadas en la Unidad Obstétrica, durante los años 19661967-1968, que el aborto representó el $14,0 \%$ de estas hospitalizaciones. Durante este mismo tiempo hubo 6.586 partos $(74,5 \%)$, lo cual significa que por cada 5 partos se atendió 1 aborto.

El aborto es en nuestro país un problema médico social de magnitud considerable, que afecta a un gran número de mujeres. Ocupa un alto porcentaje de las camas hospitalarias y para su atención médica adecuada, nuestros centros hospitalarios, deben destinar, de sus precarios presupuestos, importantes sumas de dinero.

El monto total de las sumas presupuestales del Hospital Universitario de Caldas ascendió durante los años 1966, 1967 y 1968 a la suma global de $\$ 27^{\prime} 728.000,00$. De esta cifra debió destinar $\$ 503.136,00$ para la atención del aborto hospitalario.

En otros étrminos, dedicó el 1,81\% de su presupuesto a la asistencia médica del aborto.

Durante estos 3 años 28.328 pacientes ingresaron a las Salas Generales del Hospital. Si se relaciona esta cifra con el número de abortos hospitalizados se encuentra que por cada 100 pacientes que ingresaron al hospital el $4,3 \%$ se admitió por aborto.

Durante esta misma época se transfundieron por aborto $147.615 \mathrm{cc}$. de sangre. El hospital utilizón en transfusiones gratuitas, en sus Servicios
Generales, la cantidad de 3'176.420 cc. Esto es: el aborto significó el $4,6 \%$ del total de sangre transfundida. Para entonces, cada cc. de sangre transfundida representó para el hospital la erogación de $\$ 0,21$; de donde resulta que se invirtió en transfusiones por aborto, durante este tiempo, la suma de $\$ 30.999,15 \mathrm{~m} / \mathrm{cte}$.

Resulta muy difícil valorar los daños y pérdidas económicas producidas por el aborto. El Dr. Rolando Armijo (1) anota que la tasa de letalidad en los hospitales oscila alrededor de 5 por mil más del doble que la mortalidad materna. Las secuelas y complicaciones, tanto inmediatas como tardías, comprenden una amplia gama de patología en la cual deben considerarse también los trastornos psicológicos.

Es un hecho evidente que las complicaciones son más graves y frecuentes en el aborto provocado; lo cual se explica por los siguientes hechos:

19) La apertura del huevo conduce rápidamente a la infección de su contenido, y en consecuencia, a la muerte del embrión.

2.) El desprendimiento placentario traumático no es más que parcial y abre una red vascular de considerable actividad en esta etapa de la gestación.

3:) La culminación del desprendimiento y más tarde la expulsión completa del huevo, condiciones indispensables de la hemostasia espontánea, son difícilmente realizados.

4) La placenta, respecto al feto, es muy voluminosa y se halla profundamente adherida en la pared uterina, la cual no está preparada para la evacuación útero-placentaria. 
5) El útero, durante este período de la gestación, está en reposo porque en esta época el equilibrio neuro-hormonal está regulado para asegurar su inmovilidad. Esta inactividad uterina explica las dificultades de la dilatación y del borramiento del cueIlo (10-11).

En el aborto espontáneo las complicaciones sépticas graves son excepcionales. Estas son el atributo de las maniobras abortivas criminales, realizadas en malas condiciones de asepsia, siendo los agentes causales principales el estreptococcus hemolítico, la escherichia coli, el aerobacter aerógenes, la seudomona aeruginosa, el proteus vulgaris etc.

En nuestro estudio encontramos 179 casos con aborto infectado. Todas las pacientes incluídas presentaban evidencia local y general de infección: calofrío, fiebre 38 o más, hemorragia de olor fétido, vagina caliente y diversos grados de compromiso genital, abdominal o general. Esta fue la sintomatología más frecuente. En un pequeño grupo predominaban los fenómenos de alteración del estado general, con poca reacción local, lo cual es frecuente en los cuadros de septicemia y shock bacteriémico.

\section{Clasificación}

Existen varias clasificaciones en la literatura obstétrica, en un intento por fijar normas respecto al grado de extensión o propagación de la infección a partir del útero. Son clasificaciones que se extienden desde la más simple y sencilla que engloba en una sola todas las lesiones bajo el nombre de Aborto Complicado (2), hasta las más complejas como la propuesta por Falk y col. (6) en la cual la infección comprende 6 grupos principales. Otros autores como Goodno y col. (3-8), Neuwirth y S. Robert (14) dividen la sepsis en 3 categorías y Muñoz Delgado y col. (13) consideran la división de la sepsis en cinco grados.

Nosotros, por parecernos más objetiva y fácil de aplicar desde el punto de vista clínico y fisiopatológico, acogimos al clasificación que divide la sepsis en 4 estados (18) así:

Estado I: Infección localizada en la cavidad uterina.

Estado II: Infección extendida a los anexos 0 estructuras parauterinas.

Estado 111: Pelviperitonitis o peritonitis.

Estado IV: Septicemias, Shock bacteriémico, Insuficiencia renal etc.

En la literatura nacional existen varios estudios sobre el Aborto Séptico en los cuales sus autores utilizan diversas clasificaciones.

No conocemos, hasta el momento, ningún criterio que oriente hacia una clasificación única y fácilmente aplicable. Por lo tanto, nos parece oportuno recomendar que se estudie la conveniencia de adoptar a nivel nacional una clasificación unificada, que señale normas con relación a la extensión y propagación de la infección, reúna las alteraciones patológicas y fisiopatológicas producidas por la enfermedad, que permita una orientación terapéutica definida y clínicamente pueda aplicarse con facilidad.

Los 179 casos de Aborto Séptico hallados por nosotros los presentamos en el Cuadro No 23.

El $14,5 \%$ del total de abortos analizados tenía complicaciones por infección. 
CUADRO NN 23

DISTRIBUCION PORCENTUAL DE 179 ABORTOS INFECTADOS SEGUN EL ESTADO DE INFECCION

\begin{tabular}{|c|c|c|}
\hline Clasificación & $N^{o}$ de Casos & $\%$ \\
\hline Estado I & 148 & 82,7 \\
\hline Estado II & 14 & 7,8 \\
\hline Estado III & 6 & 3,4 \\
\hline \multirow[t]{2}{*}{ Estado IV } & 11 & 6,1 \\
\hline & 179 & 100,0 \\
\hline
\end{tabular}

Su relación con el total de ingresos (8.835) es del $2,0 \%$ y si se compara con el total de partos atendidos (6.586) resulta una relación de 1 por 36.

La infección más frecuente se encontró en el estado I seguida de sepsis en los Estados II y IV respectivamente.

En el Estado III encontramos $6 \mathrm{ca}$ sos.
La conducta a la cual se sometieron estas pacientes incluyó: Elaboración de una historia clínica completa, haciendo énfasis en la posibilidad de aborto criminal (siempre se consideran infectados y con posibilidad de perforación uterina). Se investigó el antecedente de maniobras abortivas. Para la identificación de los gérmenes causales se tomaron frotis, cultivos y antibiogramas de las secreciones genitales así como hemocultivos. Otros exámenes incluyeron hemoglobina, hematocrito, leucograma, sedimentación, orina, azohemia, glicemia, creatinina, serología y hemoclasificación.

Los tejidos obtenidos del endocérvix y de la cavidad uterina fueron sometidos a estudio histológico y en algunos acsos se ordenó cultivo y antibiograma de estos productos. En los casos con presunción de patología abdominal y ante la sospecha de maniobras abortivas se solicitó radiogra-

DISTRIBUCION PORCENTUAL DE 179 ABORTOS INFECTADOS SEGUN EL ESTADO DE INFECCIDN

Porcentajes

Estado I

Estado II

Estado III

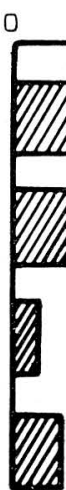

GRAFICA No 9 
Marzo-Abril 1970

Rev. Col. Obst. y Ginec.

fía simple del abdomen. Cuando el caso lo requirió se ordenaron otros exámenes especiales.

Inicialmente los casos se incluyeron dentro de uno de los 4 grupos de la clasificación y se inició la terapéutica indicada para cada caso según el esquema de tratamiento del servicio. Posteriormente el tratamiento se orientó de acuerdo con los resultados del laboratorio y la evolución clínica.

\section{Tratamiento quirúrgico}

Excepción hecha de los raspados uterinos que constituyen conducta de rutina en todo aborto incompleto, los otros procedimientos quirúrgicos fueron efectuados en su totalidad en los casos complicados con sepsis. Ellos se esquematizan en el Cuadro № 24.

\section{CUADRO Nㄴ 24}

\section{TRATAMIENTO QUIRURGICO}

\begin{tabular}{lc}
\hline Procedimiento & $N^{0}$ de Casos \\
\hline Histerectomías & 6 \\
Colpotomías & 7 \\
Histerorrafias & 4 \\
Salpinguectomía bilateral & 2 \\
Salpingo-ooforectomía unilateral & 3 \\
Laparotomía y drenaje & 5 \\
\end{tabular}

Los anteriores procedimientos quirúrgicos se ejecutaron en casos de aborto séptico con antecedentes de maniobras abortivas criminales.

En 6 casos $(0,5 \%)$ de aborto espontáneo hubo ruptura uterina accidental al practicar el raspado. Uno de ellos fue remitido por el médico que practicó el legrado en una de las poblaciones vecinas (puesto de salud). En 4 de ellos fue necesario hacer histerorrafia, los otros dos mejoraron con el tratamiento médico.

\section{Principales gérmenes encontrados en un grupo de pacientes complicadas sépticas}

Los principales gérmenes encontrados en 116 pacientes complicadas por infección fueron:

\section{CUADRO № 25}

DISTRIBUCION PORCENTUAL DE 116 PACIENTES INFECTADAS SEGUN TIPO DE GERMEN CAUSAL

\begin{tabular}{lcr}
\hline Germen & $N^{0}$ de Casos & $\%$ \\
\hline Scherichia Coli & 31 & 26,7 \\
Estafilococcus Albus & 16 & 13,8 \\
Estreptococcus Beta hemolítica & 11 & 9,5 \\
Klebsiella pneumoniae & 8 & 6,9 \\
Estreptococcus faecalis & 8 & 6,9 \\
Diplococcus pneumoniae & 7 & 6,0 \\
Estreptococcus alfa & 6 & 5,2 \\
Proteus vulgaris & 6 & 5,2 \\
Estreptococcus anaerobio & 5 & 4,3 \\
Neisseria gonorrheae & 4 & 3,4 \\
Clostridium Welchii & 4 & 3,4 \\
Aerobácter aerógenes & 3 & 2,6 \\
Pseudomonas aeruginosa & 2 & 1,7 \\
Estafilococcus dorado & 2 & 1,7 \\
Bacilo subtilis & 1 & 0,9 \\
Proteus Morganii & 1 & 0,9 \\
Alcalínenes faecalis & 1 & 0,9 \\
& 116 & 100,0 \\
\hline
\end{tabular}

El germen que se encontró con mayor frecuencia fue la Scherichia Coli $(26,7 \%)$ seguida del estafilococcus albus $(13,8 \%)$ y el estreptococcus beta hemolítico $(9,5 \%)$. También se encontraron gérmenes del tipo de clostridium Welchii; aerobácter aerógenes, las pseudomonas aeruginosa $y$ el proteus vulgaris cuyas toxinas condicionan el Shock séptico.

\section{Métodos principales utilizados para provocar el aborto}

Por lo anteriormente expuesto puede afirmarse que en nuestro medio la causa predominante en la frecuencia del aborto séptico la constituyen las maniobras abortivas realizadas por la misma paciente o por otras 
personas en pésimas condiciones de asepsia.

En las pacientes que analizamos, encontramos que la forma más usual de provocar el aborto fue introduciendo por vía vaginal diversos artefactos tales como clavos, sondas con alma metálica, tijeras, cucharas, alambres y varillas, agujas de tejer, paliIlos, cánulas, aplicadores, gasa y algodón, portaplumas etc. Otro método socorrido fue la utilización de duchas y lavados vaginales con cocimientos a base de sustancias de origen vegetal como el sauco (sambucus nigra) la ruda (planta rutácea), la altamisa - artemisa (artemisia vulgaris) y el mastuerzo (Lepidium sativum) etc. La ingestión de estas sustancias también se utilizó con fines abortivos.

También se usaron con fines abortivos la aplicación de algunas drogas occitócicas tales como la occitocina $y$ el maleato de ergonovina, drogas que se pueden adquirir fácilmente, sin fórmula médica y no están sometidas a control alguno por las autoridades sanitarias. Así mismo se utilizaron la quinina que tiene una acción occitócica y el "Mejoral". Este último lo utilizaron mezclado con jugo de limón en duchas y lavados vaginales - también por ingestión. En uno de nuestros casos se encontró que había ingerido en mezcla con jugo de limón hasta la cantidad de 20 pastas de Mejoral. Finalmente, en algunas pacientes, como método abortivo, se emplearon jeringas, peras de caucho y cánulas para introducir en la cavidad uterina a través del cuello sustancias preparadas a base de jabón, aceite, etc.

La utilización de los métodos en nuestras pacientes se discrimina así:

A 10 pacientes les habían aplicado Maleato de Ergonovina y Occitocina, pero no creemos que los occitócicos
CUADRO NN 26

DISTRIBUCION PORCENTUAL DEL METODO UTILIZADO POR 58 PACIENTES CON ABORTO CRIMINAL

MANIZALES - 1966-1968

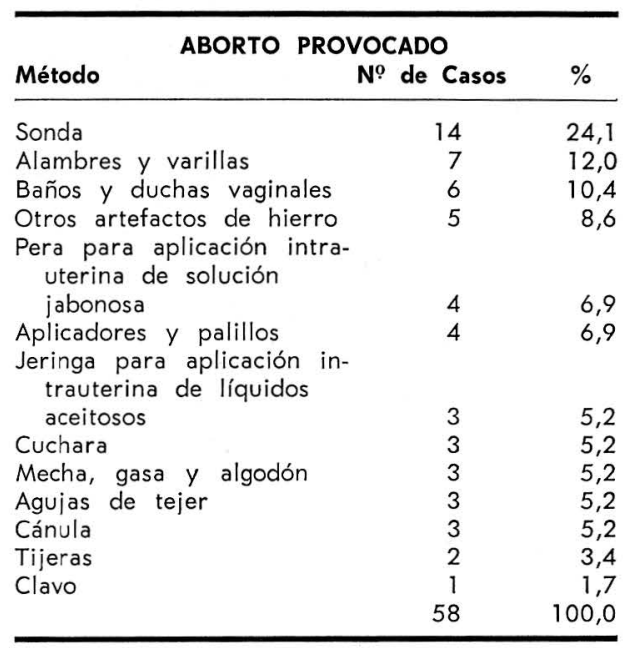

tengan mucha acción como sustancias abortivas en úteros con gestaciones normales. En casos predispuestos a la interrupción estas sustancias pueden desencadenar la evacuación del contenido uterino. En 2 pacientes se encontró la sonda: una que se retiró del canal cervical en el momento del examen y otra de la cavidad abdominal al practicar la laparotomía.

28 pacientes atribuyeron el aborto al traumatismo sufrido por una caída. Creemos que con esto la mayoría de las pacientes trataron de enmascarar la verdadera etiología del aborto.

\section{Mortalidad}

Tres pacientes murieron: Una por shock séptico, Insuficiencia Renal aguda. Septicemia por Estreptococcus Beta hemolítica. Otra presentó una peritonitis generalizada, tabicada 
DISTRIBUCION POACENTUAL DE 5 B PACIENTES SEGUN METODO UTILIZADO PARA EL ABORTO CRIMINAL

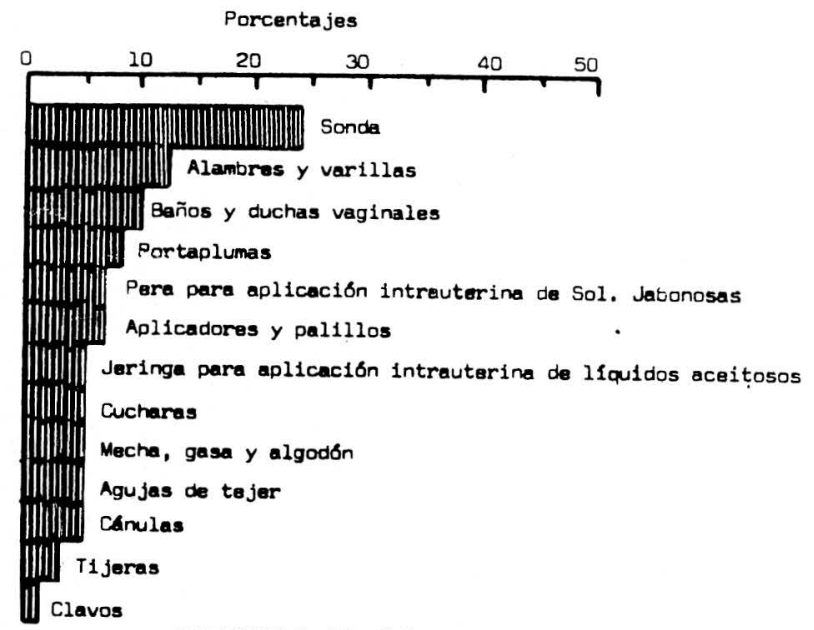

GRAFICA NN 10

con aglutinación de asas intestinales. En los cultivos se aislaron: Scherichia Coli, Proteus vulgaris y Diplococcus pneumoniae. La última presentó peritonitis generalizada a partir de una ruptura uterina. Se aislaron de los cultivos del material extraído de la cavidad abdominal Scherichia Coli, Kebsiella Pneumoniae y Estreptococcus Beta hemolítico.

Todas ingresaron al hospital con antecedentes de Aborto Provocado y en pésimas condiciones generales.

La incidencia total de mortalidad por aborto fue del $0,2 \%$.

Hacemos la siguiente relación:

Con el número total de abortos (1.229) 0,2\%.

Con el número de abortos infectados (179) $1,7 \%$.

Con el número de abortos provoca$\operatorname{dos}$ (147) $2,0 \%$.

\section{Resumen y Conclusiones}

19) De 8.835 hospitalizaciones hechas en la Unidad Obstétrica del Hospital Universitario de Caldas entre el 1\% de Enero de 1966 al 31 de Diciembre de 1968, el 74,5\% (6.586) ingresó por parto y el 14,0\% (1.229) por aborto. Se presenta la revisión y análisis de als historias clínicas de estos abortos.

2.) Ante la ausencia de signos evidentes macroscópicos de aborto solo el estudio histológico confirma este diagnóstico.

3:) Debe hacerse el estudio sistemático de todos los productos obtenidos por legrado uterino no solamente para confirmar o descartar el diagnóstico de aborto sino para descubrir otra patología.

4\%) El $80,8 \%$ de las pacientes estaba entre los decenios $30^{\circ}$ y $4{ }^{\circ}$ de la vida y el $89,0 \%$ procedía de la ciudad de Manizales. 
5?) Según la clasificación socio-económica hecha por el Hospital, la totalidad de las pacientes pertenecían a núcleos familiares de pocos ingresos y de recursos económicos limitados, con un bajo nivel cultural.

6\%) El 91,6\% se dedicaba a los oficios del hogar.

7.) El $75,0 \%$ de los abortos se presentó entre la sexta y catorceava semanas de embarazo y el 90,6\% no había asistido a Consulta Prenatal.

8.) El 46,0\% de los abortos se presentó en pacientes sin antecedentes de interrupción de embarazos anteriores, lo cual no concuerda con la teoría de Malpas.

9०) Se encontró una incidencia de aborto provocado comprobado del $12,0 \%$. No obstante, hay bases suficientes que permiten pensar en una frecuencia real mucho más alta.

10\%) En el 92,3\% los síntomas predominantes fueron la hemorragia y el dolor asociados.

11 ) En el $44,9 \%$ hubo complicaciones relacionadas con hemorragia e infección. El shock post-hemorrágico se presentó en el 16,8\% de los casos y la infección se presentó en 14,5\%. Se sugiere estudiar la posibilidad de adoptar a nivel nacional una clasificación de la sepsis post-aborto unificada.

12:) Se encontró en el grupo de estudios una incidencia de sífilis no depurada, del 8,0\%.

13) El promedio de hospitalización global fue de 3,4 días. El mayor tiempo de hospitalización fue empleado por abortos criminales complicados con sepsis.

14.) Cuando hay sospecha de maniobras abortivas criminales la pre- sencia de inflamación concomitante con vellosidades normales puede ser un indicio más en la configuración del diagnóstico de aborto criminal.

15:) El signo de Arias Stella se encuentra en el embarazo pero no autoriza para confirmar el diagnóstico de embarazo ectópico.

16.) Durante los años 1966, 1967 y 1968 el aborto significó para el Hospital Universitario de Caldas:

A) El $14,0 \%$ de las hospitalizaciones en la Unidad Obstétrica.

B) Por cada 5 partos se atendió 1 aborto.

C) Por cada 100 pacientes ingresadas a las Salas Generales del Hospital el $4,3 \%$ se admitió por aborto.

D) El $4,6 \%$ de las transfusiones se hizo a pacientes con aborto.

E) El costo total de estas transfusiones ascendió a la suma de $\$ 30$.$999,15$.

F) El Hospital empleó en la atención de los abortos hospitalarios la suma de $\$ 503.146,00$; es decir, el $1,81 \%$ del presupuesto global.

17\%) El $14,5 \%$ de los abortos presentó complicaciones por infección, lo cual representa el 2,0\% del total de abortos y el $1 \times 36$ de los partos atendidos.

18:) Las intervenciones quirúrgicas se ejecutaron en su mayoría en pacientes complicadas por aborto provocado.

19\%) Los gérmenes que se encontraron con mayor frecuencia como causantes de la complicación séptica fueron:

Scherichia Coli, 26,7\%. Estreptococcus Beta hemolítico, 9,5\%. Estafilococcus Albus, 13,8\%. 
20:) Los métodos más utilizados por este grupo de pacientes para provocar aborto fueron:

La aplicación de la sonda, alambre $y$ varillas.

21) Se encontró una incidencia de mortalidad total por aborto de $0,2 \%$. Todas murieron a consecuencia de aborto provocado criminal. Su relación con el número de abortos infectados fue del $1,7 \%$ y con el número de abortos provocados y comprobados del $2,0 \%$.

\section{Recomendaciones :}

Se recomienda estudiar la posibilidad de adoptar a nivel nacional una clasificación para el aborto séptico unificada que dé normas con relación a la extensión y propagación de la infección, permita una orientación terapéutica definida y clínicamente pueda aplicarse con facilidad.

\section{Agradecimientos :}

Quiero rendir mis más sinceros agradecimientos y mi perenne reconocimiento de gratitud y admiración a los Profesores y Médicos Residentes de la Unidad Obstétrica, así como al personal Médico y Para-Médico de los Laboratorios Clínico y de Anatomía Patológica sin cuya entusiasta y decidida colaboración no hubiera sido posible la elaboración de este estudio:

\section{BIBLIOGRAFIA}

1 ARMIJO, ROLANDO Y MONREAL, TEGUALDA. Epidemiología del aborto provocado en Santiago. San Juan, Escuela de Salubridad, Universidad de Chile, Abril de 1964. pp.: 1-32. (Mimeografiado).

2 CALATRONI, CARLOS Y RUIZ, VICENTE. Terapéutica ginecológica. 7a. ed. Buenos Aires, El Ateneo, 1954. p. 501.

3 DANFIRTH, DAVID. Spontaneous abortion. Clinical Obstetrics and Ginecology. 2 (1): 22-35. Marzo/59.

4 DEXEUS FONT, S. Y DEXEUS TRIAS D EBES, J. M. Tratado de Obstetricia. 2ad. ed. Barcelona, Salvat, 1957. pn. 1059-1099.
5 DUARTE CONTRERAS, A. y otros. Estudio completo de 235 abortos. Revista Colombiana de Obstetricia y Ginecología 15 (5): 421-428. Septiembre-Octubre 1964.

6 FALK, C. HENRY Y BLINICK, G. Management of post-abortal peritonitis. American Journal Obstetrics and Ginecology 54 (2): 315 Agosto/47.

7 GOLD, EDWIN M. Identificación del feto que corre riesgo alto. Clínicas Obstétricas y Ginecológicas No 4: 1069 1080. Diciembre/68.

8 GOODNO, A. y JOHN y otros. Management of infected abortion. American Journal Obstetrics and Ginecology 85 (1): 17. Jan. $1^{\circ}$ 1963.

9 ISAZA MEJIA, G. 270 rasnados uterinos para el aborto. Revista Colombiana de Obstetricia y Ginecolonía 11 (5): 539-549. Seotiembre-Octubre/60.

10 LEON, JUAN · otros. Manual de Obstetricia. Buenos Aires, Gumersindo F. Fernández, 1967. pp. 548-571.

11 MERGER, ROBERT y otros. Manual de Obstetricia. Barcelona, Toray-Masson, 1964. pp. 210-233.

12 MORAGUEZ B. JAIME. Clínica Obstétrica. 8a. ed. Buenos Aires, El Ateneo, 1960. pp.: 321-332.

13 MUÑOZ DELGADO, S. y otros. Tratamiento agresivo en el aborto séptico. Revista Colombiana de Obstetricia y Ginecología 11 (5) : 487-502. Septiembre-Octubre/60.

14 NEUWIRTH, S., ROBERT. Septic abortoin. American Journal Obstetrics and Gynecology 85 (1): 25 Jan. 1\%/63.

15 NOVAK, EDMUNDO y WOODRUFF, DONALD. Ginecología y Obstetricia. 2a. ed. Madrid, Alhambra, 1964. pp. 550-567.

16 PARDO VARGAS, F. V GARCES FERRER, $M$. Aspectos médico-sociales del aborto. Revista Colombiana de Obstetricia y Ginecología. 20 (4): 213-227. Julio-Agosto/69.

17 PERALTA CAYON, RAFAEL. Aborto, cesáreas previas, controversias clínicas y terapéuticas. Bogotá, Omnia, 1962. pp. 6.

18 SANTAMARIA P., LUIS EDUARDO. Aborto séntico y maniobras abortivas. Revista Colombiana de Obstetricia y Ginecología. 17 (4) : 273-290. Julio-Agosto/66.

19 TAYLOR, STEWART. Obstetricia de Beck. 8a. ed. México, Interamericana, 1968. pp.: 298-309. 